\title{
The identification of a new actin-binding region in p57
}

\author{
Chang Zhen Liu ${ }^{1}$, Yong Chen ${ }^{1}$, Sen Fang Sui ${ }^{1}$ \\ ${ }^{1}$ Department of Biological Sciences and Biotechnology, State Key Laboratory of Biomembranes, Tsinghua University, Beijing 100084, \\ China
}

The actin-binding protein $\mathrm{p} 57$ is a member of mammalian coronin-like proteins. The roles of this protein in phagocytic processes conceivably depend on its interactions with $\mathrm{F}$-actin. Two regions, $\mathrm{p} 57^{1-34}$ and $\mathrm{p} 57^{111-204}$, were previously reported to be actin-binding sites. In this study, we found that the C-terminal region of p57, p5 $7^{297-461}$, also possessed F-actin binding activity. Furthermore, the leucine zipper domain at the C-terminus of $\mathrm{p} 57^{297-461}$ was essential for this actin-binding activity. The F-actin cross-linking assay revealed that the region contained in $\mathrm{p} 57^{297-461}$ was sufficient to cross-link actin filaments. Our results strongly suggested that there was a new actin-binding region at the C-terminus of p57.

Cell Research (2006) 16:106-112. doi:10.1038/sj.cr.7310014; published online 16 January 2006

Keywords: actin-binding protein, p57, actin cytoskeleton, leucine zipper

\section{Introduction}

Coronin-like proteins are a family of actin-binding proteins that are represented in a large variety of eukaryotic cells from yeast to human [1]. The first family member was characterized in Dictyostelium discoideum and was shown to play crucial roles in various cell functions, including cell locomotion, phagocytosis, and cytokinesis [2-4]. p57, also named coronin1, was the first coronin-like protein identified in mammals $[1,5]$. The $57 \mathrm{kDa}$ protein reveals an open reading frame of 1386 base pairs encoding 461 amino acids. Similar to the other coronin-like protein family members, p57 has a central region that comprises five WD repeats, which is speculated to create a stable platform that can interact reversibly with other proteins [6]. The Nterminal extension of p57 is composed of approximately 70 amino acid residues conserved in most mammalian coronin-like proteins. The $\mathrm{C}$-terminal extension contains a

Correspondence: Sen Fang Sui

Tel: +86-10-62784768;

E-mail: suisf@mail.tsinghua.edu.cn

Abbreviations: G-actin (globular actin); F-actin (filamentous actin); GST (glutathione $S$-transferase); RT-PCR (reverse transcription-polymerase chain reaction)

Received 17 Jun 2005; revised 19 Oct 2005; accepted 22 Oct 2005, published online 16 January 2006 leucine zipper domain, which evolved from a coiled coil of the coronin-like protein family and was reported to mediate the homotypic dimerization or trimerization of p57 [7-9].

It has been reported that p57 plays essential roles in the generation of early phagosomes and maturation of phagolysosome in phagocytes $[10,11]$. The transient accumulation of p57 on early phagosomes and the gradual disassociation of $\mathrm{p} 57$ from the phagosomal membrane after phagosomes maturation had the same kinetics as those of F-actin [11], which suggested that p57 might take part in the processes of phagocytosis by interacting with F-actin. However, its precise role associated with actin cytoskeleton remodeling during phagocytic processes and the underlying mechanisms of interaction between p57 and F-actin have yet to be defined.

Due to the importance of the interaction between p57 and actin, and the ambiguity of the underlying mechanisms, the actin-binding sites of $\mathrm{p} 57$ have been investigated. A previous study suggested that two regions within $\mathrm{N}$-terminal and central part of p57 (Met-1 to Asp-34 and Ile-111 to Glu-204) are responsible for actin binding [12]. However, it has been reported that the deletion of the C-terminal 65 amino acids from Xcoronin, a Xenopus homologue of coronin, significantly reduces its actin-binding activity [13]. In another report, the F-actin interaction of human coronin 3 (Hcoronin3) is mediated by its C-terminus [14]. These studies suggest that the $\mathrm{C}$-terminus of $\mathrm{p} 57$ may contribute to 
its actin binding. In this study, we examined actin-binding activity of the C-terminus and confirmed that p5 $7^{297-461}$, a $\mathrm{C}$-terminal region of $\mathrm{p} 57$, had the activity of actin binding and F-actin cross-linking. We also found that the leucine zipper domain might be essential for the actin-binding activity of $\mathrm{p} 57^{297-461}$.

\section{Materials and methods}

Construction of plasmids expressing full-length and deletion mutants of $p 57$ in E. coli and mammalian cells

The full-length cDNA of $\mathrm{p} 57$ was prepared by RT-PCR amplification of mRNA from U937 cells. PCR primers (sense primer: 5'-GTC GGA TCC ATG AGC CGG CAG GTG G-3', and antisense primer: 5'-GTC GAA TTC CTA CTT GGC CTG GAC TGT CTC-3') were synthesized based on the sequence of the coding region of Homo sapiens coronin 1A (GenBank accession No. XM055133). The construction for expression of full-length $\mathrm{p} 57$ in $E$. coli was prepared by digestion of the PCR products with BamHI and EcoRI, and then cloned into vector pGEX-6P-1 (Amersham Pharmacia). The constructions for expression of deletion mutants (p57 $7^{297-461}$ and $\mathrm{p} 57^{386-461}$ ) (Figure 1) in E. coli were prepared by the same procedure, and the primers were used as follows: a. (for $\mathrm{p} 57^{297-461}$ ): sense primer: $5^{\prime}$-GTA GGA TCC ATC ACT TCC GAG GCC CCT TTC-3', and antisense primer: 5'-GTC GAA TTC CTA CTT GGC CTG GAC TGT CTC3'; b. (for p5 $7^{386-461}$ ): sense primer: 5'-GTC GGA TCC CCC CTC CTC ATC TCC CTC AAG-3', and antisense primer: 5'-GTC GAA TTC CTA CTT GGC CTG GAC TGT CTC-3'. The mutagenesis of Leu-441 and Leu-447 of p5 $7^{297-461}$ to alanine (p5 2977-461/Mut) (Figure 1) was performed by PCR amplification with mutagenic primers: (sense primer: 5'-GTA GGA TCC ATC ACT TCC GAG GCC CCT TTC-3' and antisense primer: 5'-CTA CTT GGC CTG GAC TGT CTC CTC CAG CCT GTC CAA GCG CTT CTG GAG CTC CTG CAC CGT GGC CTG GAG CTT CCG-3'). Plasmids expressed in mammalian cells were prepared by corresponding digestion of constructed pGEX-6P-1 fusion plasmids with BamHI and EcoRI, and subcloning the digested products into vector pcDNA 4.0/His-max (Invitrogen). Proteins encoded from these plasmids were expressed as fusion proteins with an N-terminal Xpress ${ }^{\mathrm{TM}}$ tag (Invitrogen). Constructions described above were confirmed by DNA sequencing (Sangon Corp, China).

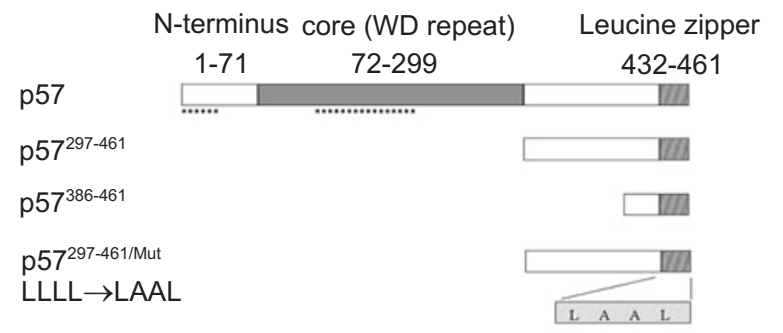

Figure 1 Schematic views of p57 and its deletion mutants. The WD repeat region (solid box) and the leucine zipper-containing region (hatched) are highlighted. The underlines indicate the two actin-binding regions reported in study by Oku et al [12].

\section{Expression and purification of GST fusion proteins}

E. coli BL21 transformed with constructed plasmids was used to express GST fusion proteins of full-length and deletion mutants of p57. The expression and purification of GST fusion proteins were preformed according to the instruction of GST Gene Fusion System (Amersham). The GST moiety of GST-p5 $7^{297-461}$ was cut off by treatment of the washed fusion protein-bound Glutathione-Sepharose 4B beads with PreScission ${ }^{\mathrm{TM}}$ Protease (Amersham).

\section{F-actin co-sedimentation assay}

Actin-binding assays in vitro were performed to investigate the activity of fusion proteins to bind actin [7]. G-actin ( $3 \mu \mathrm{M}$, Sigma) was incubated in F-actin buffer containing $20 \mathrm{mM}$ imidazole $(\mathrm{pH}$ 7.0), $50 \mathrm{mM} \mathrm{KCl}, 1 \mathrm{mM}$ DTT, $5 \mathrm{mM}$ ATP, $2 \mathrm{mM} \mathrm{MgCl}_{2}$, and 5 $\mathrm{mM} \mathrm{CaCl}{ }_{2}$ for $40 \mathrm{~min}$ at $25^{\circ} \mathrm{C}$ to be assembled into F-actin. Various fusion proteins were incubated with pre-assembled $\mathrm{F}$-actin for $40 \mathrm{~min}$ at $25^{\circ} \mathrm{C}$. After the incubation, the reaction mixtures were ultracentrifuged at $100,000 \times \mathrm{g}$ for $30 \mathrm{~min}$ at $4^{\circ} \mathrm{C}(\operatorname{step~} 1)$. The pellets were resuspended in $\mathrm{F}$-actin buffer and transferred to new tubes for another ultracentrifugation at $100,000 \times \mathrm{g}$ for $30 \mathrm{~min}$ at $4^{\circ} \mathrm{C}$ (step 2 ). The supernatants of step $1(\mathrm{~S})$, the pellets of step $2(\mathrm{P})$, and the total reaction mixtures $(\mathrm{T})$ were resolved in SDS-PAGE loading buffer and subjected to SDS-PAGE ( $8 \%$ gel), followed by staining with Coomassie brilliant blue R-250. The procedures for conducting Factin cross-linking experiments were similar to those for actin-binding assays with slight modifications that the mixture was centrifuged at $15,000 \times \mathrm{g}$ for $10 \mathrm{~min}$ at $4^{\circ} \mathrm{C}$ [15] instead of $100,000 \times \mathrm{g}$ for $30 \mathrm{~min}$ at $4{ }^{\circ} \mathrm{C}$, and the samples were subjected to SDS-PAGE (12\% gel). Pre-assembled F-actin was used as a control.

\section{Cell culture and transfection}

U937 cells and COS-1 cells (American Type Culture Collection) were grown respectively in RPMI 1640 medium (Hyclone) and DMEM (Invitrogen) supplemented with $10 \%$ heat inactivated fetal calf serum (Hyclone), ampicillin $(100 \mu \mathrm{g} / \mathrm{ml})$ and streptomycin $(100$ $\mu \mathrm{g} / \mathrm{ml})$ at the standard cell culture condition $\left(37^{\circ} \mathrm{C}\right.$, humidified $5 \%$ $\mathrm{CO}_{2}$ in air). Plasmids pcDNA 4.0/p57, pcDNA 4.0/p5 $7^{297-461}$, pcDNA $4.0 / \mathrm{p} 57^{386-461}$, and pcDNA 4.0/p5 $7^{297-461 / \text { Mut }}$ were introduced into COS1 cells $\left(5 \times 10^{5}\right.$ cells/well) by lipofectamine ${ }^{\mathrm{TM}} 2000$ (Invitrogen) in 6-well plates according to the manufacturer's instructions. After that, cells were maintained for $48 \mathrm{~h}$ at standard cell culture conditions. To detect the expressed proteins, aliquots of the cells transfected with plasmids were resolved in SDS-PAGE loading buffer and subjected to SDS-PAGE (12\% gel), followed by immunoblotting analysis with anti-Xpress ${ }^{\mathrm{TM}}$ monoclonal antibody (Invitrogen). The blots were detected by enhanced chemiluminescence (ECL) (Amersham).

\section{Cross-linking of $p 7^{297-461}$ and $p 57^{297-461 / M u t}$ expressed in COS- 1 cell}

COS- 1 cells transfected with plasmids pcDNA 4.0/p5 $7^{297-461}$ or pcDNA 4.0/p5 $7^{297-461 / M u t}$ for $48 \mathrm{~h}$ were washed twice with ice-cold phosphate buffered saline pH 7.4 (PBS), and scraped into $0.5 \mathrm{ml}$ PBS. Disuccinimidyl suberate $(\mathrm{DSS})(1 \mathrm{mM})$ prepared as a $10 \times$ stock solution in dimethyl sulfoxide (DMSO) was used for cross-linking. The cross-linking reactions were allowed to proceed for $1 \mathrm{~h}$ on ice and terminated for $30 \mathrm{~min}$ with $50 \mathrm{mM}$ Tris $\mathrm{pH}$ 7.5. Aliquots from the reaction mixtures were subjected to immunoblotting analysis described above.

\section{Immunofluorescence microscopy}


The transfected COS-1 cells were plated onto poly-L-lysine coated $12 \mathrm{~mm}$ glass cover slips. Actin skeletal frameworks were prepared according to the reported method [16]. After incubation for $30 \mathrm{~min}$ at room temperature with PBS containing 1\% BSA, cells were coincubated with mouse anti-Xpress ${ }^{\mathrm{TM}}$ antibody (1:1000, Invitrogen) which recognizes the $\mathrm{N}$-terminal Xpress ${ }^{\mathrm{TM}}$ tag of expressed fusion proteins, and goat anti-actin antibody (I-19) (1:500, Santa Cruz) for $3 \mathrm{~h}$ at room temperature. After being washed with PBS, the cells were incubated with rhodamine-labeled rabbit anti-goat IgG (1:400, Santa Cruz) for $20 \mathrm{~min}$ in the dark at room temperature. After further washing steps, the cells were incubated with FITC-labeled goat anti-mouse $\operatorname{IgG}(1: 400$, Santa Cruz) for $20 \mathrm{~min}$ in the dark at room temperature. Fluorescently labeled cells were washed three times with PBS for $5 \mathrm{~min}$ and then mounted on slide glass with $90 \%$ glycerol. Samples were analyzed by using a Fluorescence Microscope (Nikon Eclipse E800).

\section{Electron Microscopic Analysis}

Actin filaments cross-linking was visualized by electron microscopy. Pre-assembled F-actin $(2 \mu \mathrm{M})$ or the mixture of F-actin and purified $\mathrm{p} 57^{297-461}$ at molar ratios of 3:1 were incubated in F-actin buffer for $30 \mathrm{~min}$ at $25^{\circ} \mathrm{C}$. After the incubation, the reaction mixtures were centrifuged at low speed $(15,000 \times \mathrm{g})$ for $10 \mathrm{~min}$ at $4^{\circ} \mathrm{C}$, and the pellets were resuspended for electron microscopic analysis. Aliquots from both sets of reactions were spotted onto copper grids, negatively stained with $1 \%$ aqueous uranyl acetate, and examined by using a transmission electron microscope (Philips CM120).
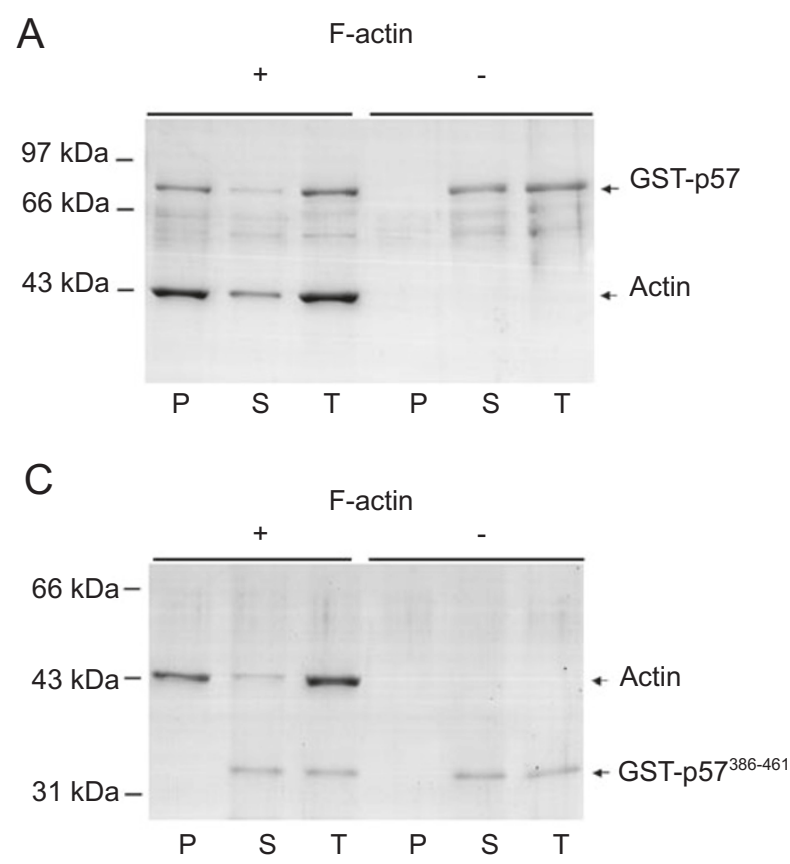

\section{Results and disscussion}

p5 $7^{297-461}$ possesses the activity of actin binding

To examine whether the C-terminus of $\mathrm{p} 57$ contains a putative actin-binding region, the actin-binding activities of full-length $\mathrm{p} 57$ and two C-terminal fragments, p57 297 ${ }^{461}$ and $\mathrm{p} 57^{386-461}$ (Figure 1), were analyzed by the F-actin co-sedimentation assay in vitro. If fusion proteins have the activity of actin binding, they would co-precipitate along with F-actin by ultracentrifugation [7, 17]. In this experiment, as a positive control, GST-p57 was detected in the pellet in the presence of F-actin, but not in the absence of F-actin (Figure 2A). Similarly, GST-p $57^{297-461}$ was detected in the pellet only in the presence of F-actin (Figure 2B). In contrast, in both the absence and presence of F-actin, GST-p5 $7^{386-461}$, a fusion protein previously reported having no actin-binding activity [12], was found only in the supernatant (Figure 2C). These results indicated that the purified recombinant protein GST-p57 $7^{297-461}$ possessed the capability to bind F-actin.

The actin-binding activities of full-length $\mathrm{p} 57$ and p $57^{297}$ ${ }^{461}$ were then compared by F-actin co-sedimentation assay in vitro. As shown in Figure 2D, in the GST-p57 group, after incubation with F-actin and ultracentrifugation, most
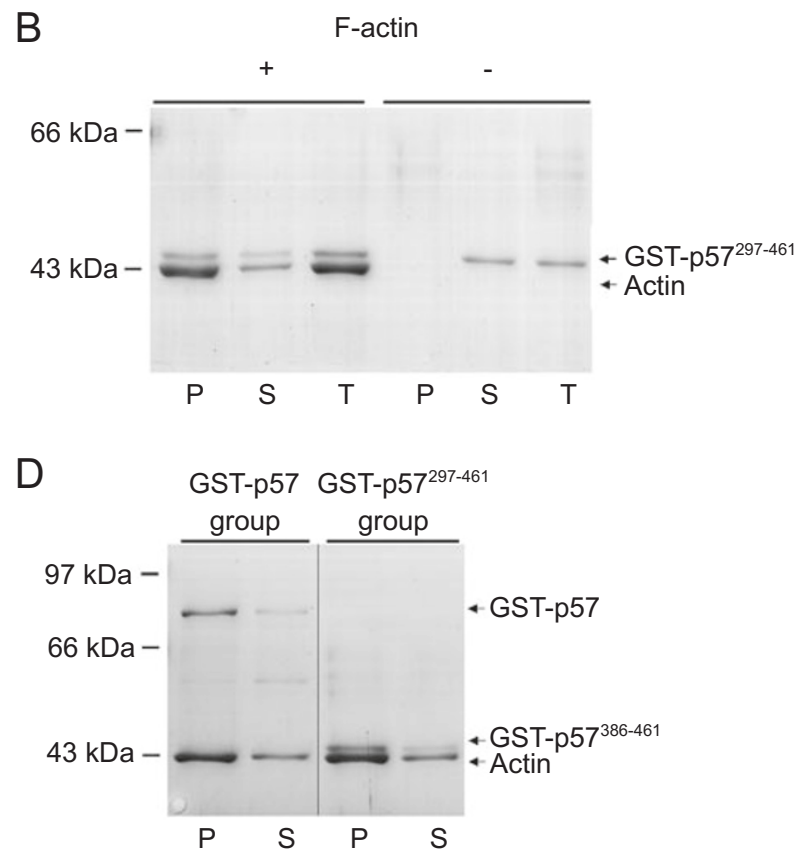

Figure 2 In vitro co-sedimentation assay of GST fusion proteins with F-actin. After mixtures were sedimented by ultracentrifugation, fractions were subjected to SDS-PAGE. T, total reaction mixture; S, ultracentrifuged supernatant; P, ultracentrifuged precipitate. Fusion proteins GST-p57 (A), GST-p5 $7^{297-461}$ (B) and GST-p57 $7^{386-461}$ (C) were incubated with (+) or without (-) F-actin for co-sedimentation assay. (D) Equal mole amounts of GST-p57 and GST-p5 $7^{297-461}$ were incubated with the same concentrations of F-actin for co-sedimentation assay. 
of GST fusion protein was precipitated into pellet (P) with a small fraction remaining in the supernatant. In the GSTp5 $7^{297-461}$ group, a similar result was obtained. The results of comparison indicated that $\mathrm{p} 57^{297-461}$ possessed similar actinbinding activity as full-length p57, suggesting the potential important role of this region in actin binding of $\mathrm{p} 57$.

The binding activity of $\mathrm{p} 57^{297-461}$ to actin cytoskeleton was further analyzed in vivo by immunofluorescence co-localization studies. First, the expressions of full-length p57, p 5 $7^{297-461}$ and p $57^{386-461}$ with Xpress-tag in COS-1 cells were identified by immunoblotting analysis. The results showed that these proteins were expressed as expected $(57 \mathrm{kDa}, 23$ $\mathrm{kDa}$ and $13 \mathrm{kDa}$, respectively) and the expression levels of them were similar (Figure 3A). Then cells were treated with $0.5 \%$ Triton $\mathrm{X}-100$ before fixation to release most cytosol protein [16], avoiding the interference of unbinding expressed proteins to the observation of immunofluorescence co-localization. The expressed Xpress-tag fusion proteins and actin cytoskeleton were stained by antibody conjugated with FITC and rhodamine respectively, and were observed by fluorescence microscopy. Full-length p 57 and $\mathrm{p} 57^{297-461}$ (green color) were both demonstrated partial co-localization (arrowheads) with cortical actin cytoskeletons (red color) (Figure 3B). In contrast, p5 $7^{386-461}$ (green color), which did not exhibit actin-binding activity in vitro, was not co-localized with cortical actin cyoskeletons (red color) (Figure 3B). These results confirmed that p57 $7^{297-461}$ had the similar activity to bind actin cytoskeleton in vivo as full-length $\mathrm{p} 57$. The results from immunofluorescence co-localization analysis were in good agreement with those of the co-sedimentation assay in vitro.

Previous study demonstrated that a p57 molecule possesses two regions responsible for binding $\mathrm{F}$-actin but neither exists at the C-terminus [12]. In this study, we found that the C-terminal region of $\mathrm{p} 57, \mathrm{p} 57^{297-461}$, had the similar actin-binding property as full-length $\mathrm{p} 57$, as demonstrated by co-sedimentation of expressed protein with F-actin in vitro and co-localization of expressed protein with actin cytoskeleton in vivo. These results revealed that the C-terminal region of p 57 might also be responsible for binding $\mathrm{F}$-actin which was consistent with actin-binding sites of other coronin-like proteins such as Xcoronin and Hcoronin3 [13, 14].

\section{Leucine zipper domain is essential to actin-binding activ- ity of $p 57^{297-461}$}

In study by $\mathrm{Oku}$ et al [12], two C-terminal regions, p 5 $7^{297-429}$ and $\mathrm{p} 57^{372-461}$, were examined for actin-binding activity while they were both found to have no actinbinding activity. In contrast, the whole length of these two C-terminal regions, $\mathrm{p} 57^{297-461}$, was shown to have the actin-binding activity in this study. The conflict between the actin-binding activities of the separated fragments and that of the whole length region impelled us to explore further. It has been reported that the last 30 amino acids at the C-terminus of $\mathrm{p} 57$ (residues 432-461) form a leucine zipper domain [7] (Figure 1). Since p5 $7^{297-461}$ contains the leucine zipper domain, while $\mathrm{p} 57^{297-429}$ does not, the effect of this domain on actin-binding activity of $\mathrm{p} 57^{297-461}$ was

A

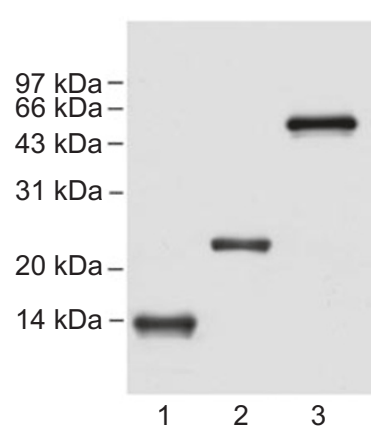

$\mathrm{B}$

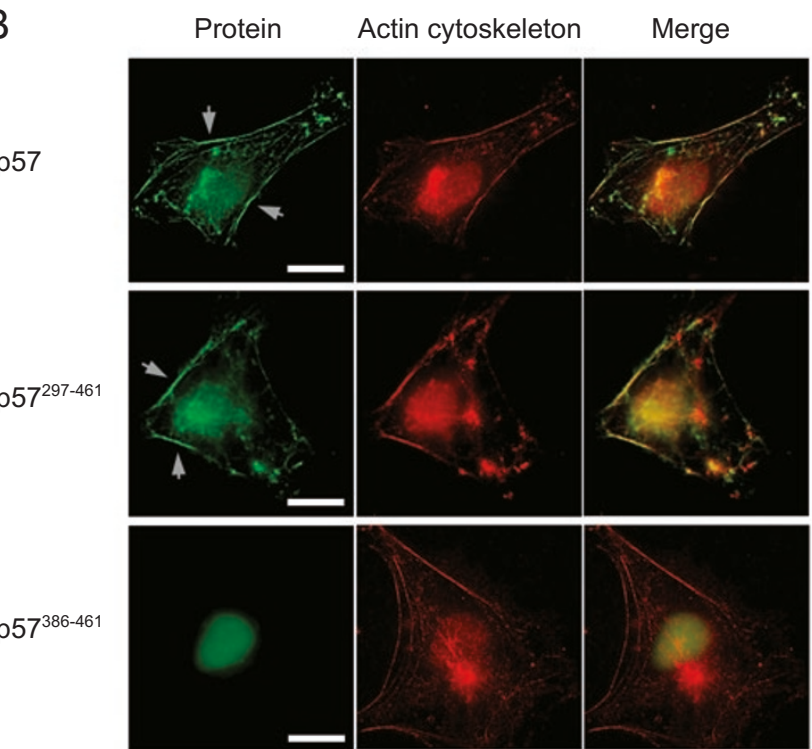

Figure 3 Co-localization analysis of p57 and its deletions with actin cytoskeleton in COS-1 cells. (A) Imunoblotting analysis. Expression plasmids pcDNA 4.0/p57, pcDNA 4.0/p5 $7^{297-461}$ and pcDNA $4.0 / \mathrm{p} 57^{386-461}$ were transiently expressed in COS- 1 cells. Aliquots of cells were subjected to SDS-PAGE, followed by immunoblotted by anti-Xpress ${ }^{\mathrm{TM}}$ monoclonal antibody; 1, p5 $7^{386-461}$ group; 2, p5 $7^{297-461}$ group; 3, p57 group. (B) Co-localization analysis. Expressed proteins and actin cytoskeleton were stained by anti-Xpress ${ }^{\mathrm{TM}}$ antibody and anti-actin antibody, followed by secondary antibodies conjugated with FITC or rhodamine respectively. Images were acquired by fluorescence microscopy. Arrowheads marked areas of cortical localization of the expressed proteins. Scale bar $=20 \mu \mathrm{m}$. Experiments were performed more than three times with representative data shown. 
investigated.

Firstly, two leucine residues (Leu-441 and Leu-447) out of the four that constitute the leucine zipper structure were replaced with alanine residues to destruct the leucine zipper domain. The destructive effect of the point mutation was then confirmed by a chemical cross-linking assay in cells. After p5 $7^{297-461}$ and p5 $7^{297-461 / M u t}$ were expressed in COS-1 cells, the cross-linking agent DSS was added to assess whether expressed proteins formed oligomers or not. The results from western blotting revealed that cross-linking of $557^{297-461}$ by DSS led to the appearance of a dimer band (46 kDa, the monomer is $23 \mathrm{kDa}$ ) (Figure 4A), which was consistent with the report of Oku et al [8] since no trimer or other higher-molecular-weight band was observed. However, in the $\mathrm{p} 57^{297-461 / \mathrm{Mu}}$ sample, no dimer band was detected (Figure 4A). The results of the cross-linking experiment indicated that the point mutation destructed the leucine zipper domain effectively, which induced the dissociation of $\mathrm{p} 57^{297-461}$ dimer.

The actin-binding activity of $\mathrm{p} 57^{297-461 / M u t}$ was then examined. In co-sedimentation assay in vitro, most of GST-p5 $7^{297-461}$ protein co-sedimented with F-actin; however, little of GST-p5 $7^{297-461 / M u t}$ protein was detected in the pellet (Figure 4B). The results of immunoblotting analysis
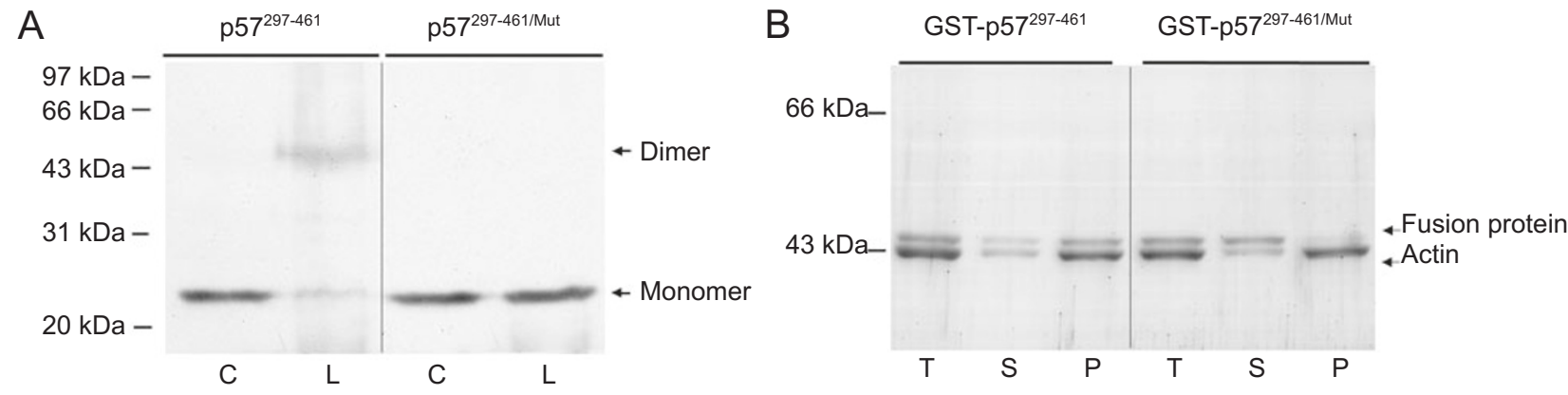

C

D

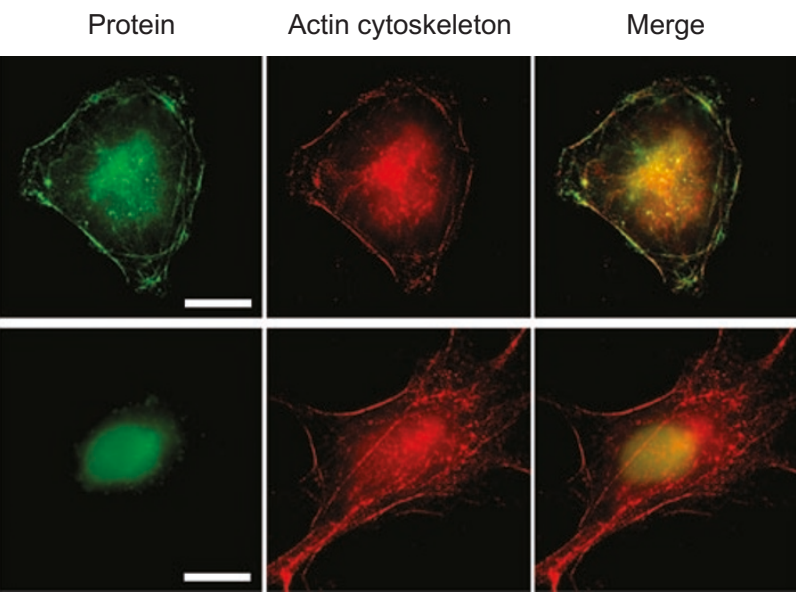

Figure 4 Effect of introduction of mutation into the leucine zipper domain of p5 $7^{297-461}$ on the actin-binding activity. (A) Cross-linking assay of p5 $7^{297-461}$ and p57 $7^{297-461 / M u t}$ expressed in COS-1 cell. Expression plasmids pcDNA 4.0/p5 $7^{297-461}$ and pcDNA 4.0/p57 297-461/Mut were introduced in COS-1 cells and expressed proteins were cross-linked by DSS. Cell fractions were subjected to SDS-PAGE and the monomer and dimer form of expressed $\mathrm{p} 57^{297-461}$ and $\mathrm{p} 57^{297-461 / \mathrm{Mut}}$ were detected by immunoblotting analysis with anti-Xpress ${ }^{\mathrm{TM}}$ monoclonal antibody; C, control group; L, cross-linking group. (B) In vitro co-sedimentation assay of GST-p57 $7^{297-461}$ and GST-p57 ${ }^{297}$ ${ }^{461 / M u t}$ with F-actin. After each fusion protein was incubated with F-actin in F-actin buffer, the mixtures were sedimented by ultracentrifugation, and fractions were subjected to SDS-PAGE. T, total reaction mixture; S, ultracentrifuged supernatant; P, ultracentrifuged precipitate. (C) Imunoblotting analysis. Expression plasmids pcDNA 4.0/p5 $7^{297-461}$ and pcDNA 4.0/p5 $7^{297-461 / \text { Mut }}$ were transiently expressed in COS-1 cells. Aliquots of cells were subjected to SDS-PAGE, followed by immunoblotted by anti-Xpress ${ }^{\mathrm{TM}}$ monoclonal antibody; 1, p5 $7^{297-461}$ group; 2, p5 $7^{297-461 / \text { Mut }}$ group. (D) Co-localization analysis of p $57^{297-461}$ and p5 $7^{297-461 / \text { Mut }}$ with actin cytoskeleton in COS-1 cells. Expressed proteins and actin cytoskeleton were stained by anti-Xpress antibody and anti-actin antibody, followed by secondary antibody conjugated with FITC or rhodamine respectively, and images were acquired by fluorescence microscopy. Scale bars, $20 \mu \mathrm{m}$. Experiments were performed more than three times with representative data shown. 
showed that $\mathrm{p} 57^{297-461}$ and $\mathrm{p} 57^{297-461 / \mathrm{Mut}}$ in COS-1 cells were expressed as expected (both $23 \mathrm{kDa}$ ) and the expression levels of them were similar (Figure 4C). Then the results from immunofluorescence co-localization analysis indicated that the distribution of $\mathrm{p} 57^{297-461 / \text { Mut }}$ was different from that of $\mathrm{p} 57^{297-461}$ (Figure 4D), but similar to that of $\mathrm{p} 57^{386-461}$ (Figure 3B), which has no actin-binding activity. The above results suggested that the leucine zipper domain was essential for the actin-binding activity of p $57^{297-461}$.

The leucine zipper-containing region has no actin-binding activity, based on the actin-binding activity of p $57^{372-461}$ in report of Oku et al [12] and actin-binding activity of p5 $7^{386-461}$ in the present study (Figure 2C and 3B). However, this domain is important for actin-binding activity of $\mathrm{p} 57^{297-461}$. This conclusion is supported by studies of several proteins whose biological functions are affected by the leucine zipper domain [18-20]. Moreover, the N-terminal part of $\mathrm{p} 57^{297-461}$ (the region located among the residues 297-386) has no actin-binding activity, based on the actinbinding activity of $\mathrm{p} 57^{297-429}$ in report of Oku et al. [12] and actin-binding activity of $\mathrm{p} 57^{297-461 / \mathrm{Mut}}$ in the present study (Figure 4B and 4D), in both of which the contribution of the leucine zipper domain to actin binding was lacked. However, this region is also important for actin-binding activity of $\mathrm{p} 57^{297-461}$, judged from the difference of actinbinding activity between $\mathrm{p} 57^{297-461}$ and $\mathrm{p} 57^{386-461}$. Therefore, it is suggested that at least the leucine zipper-containing region and the $\mathrm{N}$-terminal part of $\mathrm{p} 57^{297-461}$ are contained in the potential new actin-binding region at $\mathrm{C}$-terminus of $\mathrm{p} 57$, since both the two regions are required for actin binding of $\mathrm{p} 57^{297-461}$.

Furthermore, the results of this study showed that the potential new actin-binding region in $\mathrm{p} 57^{297-461}$ was active only in the case of the integrity of the leucine zipper domain since the introduction of point mutation into the leucine zipper domain resulted in the complete loss of the actin-binding activity of $\mathrm{p} 57^{297-461}$ (Figure 4). The leucine zipper domain is closely related to the dimerization (or oligomerization) of p57 molecule [8, 9]. Therefore, we suppose that the dimerization (or oligomerization) of the p5 $7^{297-461}$ monomers may lead to the conformational change in the region surrounding the actin-binding site, which results in the presence of the actin-binding activity. This hypothesis seems reasonable for the similar contributions of the dimerizations to the conformational changes in relation to the biological functions reported in other proteins $[21,22]$, although these dimerizations are not mediated by the leucine zipper domain. Further structural analysis of p57 may examine this hypothesis and contribute to understand the underlying mechanism.

p5 $7^{297-461}$ can cross-link actin filaments
Since $\mathrm{p} 57^{297-461}$ has the actin-binding activity and is a homodimer through the leucine zipper domain [8], its activity to cross-link actin filaments was further investigated. p5 $7^{297-461}$ without GST tag was used to cross-link pre-assembled actin filaments and a low speed co-sedimentation assay was utilized to test the effect of cross-linking [23]. At low speed $(15,000 \times \mathrm{g})$, neither F-actin nor $\mathrm{p} 57^{297-461}$ alone was pelleted upon centrifugation (Figure 5). However, addition of $\mathrm{p} 57^{297-461}$ to pre-assembled actin filaments caused co-precipitation of the complex (Figure 5). Moreover, ex-

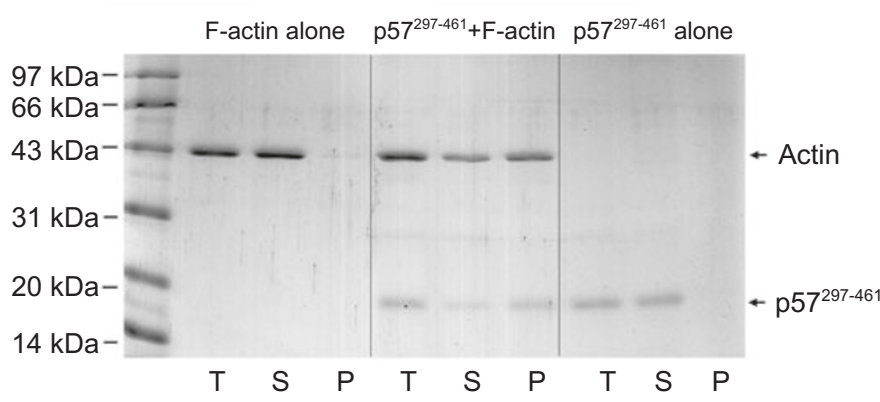

Figure 5 In vitro F-actin cross-linking assay of $\mathrm{p} 57^{297-461}$. Purified p5 $7^{297-461}$ without GST tag, F-actin or the mixture of them was sedimented at low speed $(15,000 \times \mathrm{g}, 10 \mathrm{~min})$. The fractions were subjected to SDS-PAGE. T, total reaction mixture; S, ultracentrifuged supernatant; P, ultracentrifuged precipitate.

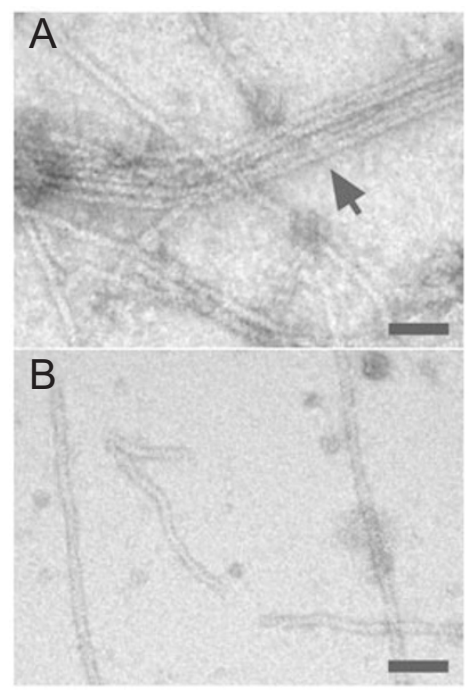

Figure 6 Visualization of actin filaments cross-linking by elelctron microscopy. F-actin or the mixture of $\mathrm{p} 57^{297-461}$ and F-actin was sedimented at low speed $(15,000 \times \mathrm{g}, 10 \mathrm{~min})$. The pellets were resuspended, negatively stained and then examined by electron microscopy; (A) sample of the mixture of p5 $7^{297-461}$ and F-actin; (B) sample of F-actin alone. Arrowhead marks cross-linked actin filaments. Scale bar $=50 \mathrm{~nm}$. 
amination of samples by electron microscopy showed that F-actin cross-linking networks formed only in the presence of p57 $7^{297-461}$ (Figure 6). The results from the co-sedimentation assays and electron microscopy indicate that $\mathrm{p} 57^{297-461}$ had the activity of cross-linking actin filaments in vitro.

It has been reported that the coronin-like proteins from budding yeast (Saccharomyces cerevisiae, Crn1p) can cross-link actin filaments into bundles and more complex networks [24]. The filament cross-linking activity of Crn1p is shown to depend on its C-terminal coiled-coil domain. Our study demonstrated that the F-actin cross-linking activity might be applicable to other coronin-like proteins including $\mathrm{p} 57$, since the C-terminal region of $\mathrm{p} 57$, p5 $57^{297}$ ${ }^{461}$, was efficient to cross-link actin filaments.

Based upon our works, as well as previous studies [12], we conclude that there are at least three regions responsible for actin binding of $\mathrm{p} 57$. The presence of multiple actinbinding regions on p57 may not only enhance the interaction between the protein and F-actin, but also contribute to the protein activity regulation (e.g. fixation of protein in a functional state when they bind with F-actin). These hypotheses await further investigation.

\section{Acknowledgement}

This work was supported by the National Basic Research Program of China (No. 2004CB720005).

\section{References}

1 de Hostos EL. The coronin family of actin-associated proteins. Trends Cell Biol 1999; 9:345-50.

2 Maniak M, Rauchenberger R, Albrecht R, et al. Coronin involved in phagocytosis: dynamics of particle-induced relocalization visualized by a green fluorescent protein Tag. Cell 1995; 83:91524.

3 de Hostos EL, Bradtke B, Lottspeich F, et al. Coronin, an actin binding protein of Dictyostelium discoideum localized to cell surface projections, has sequence similarities to $\mathrm{G}$ protein beta subunits. EMBO J 1991; 10:4097-104.

4 de Hostos EL, Rehfuess C, Bradtke B, et al. Dictyostelium mutants lacking the cytoskeletal protein coronin are defective in cytokinesis and cell motility. J Cell Biol 1993; 120:163-73.

5 Ferrari G, Langen H, Naito M, Pieters J. A coat protein on phagosomes involved in the intracellular survival of mycobacteria. Cell 1999; 97:435-47.

6 Smith TF, Gaitatzes C, Saxena K, Neer EJ. The WD repeat: a common architecture for diverse functions. Trends Biochem Sci 1999; 24:181-5.

7 Suzuki K, Nishihata J, Arai Y, et al. Molecular cloning of a novel actin-binding protein, p57, with a WD repeat and a leucine zipper motif. FEBS Lett 1995; 364:283-8.

8 Oku T, Itoh S, Ishii R, et al. Homotypic dimerisation of the actin- binding protein $\mathrm{p} 57 /$ coronin-1 mediated by a leucine zipper motif in the C-terminal region. Biochem J 2005; 387(Pt 2):325-31

9 Gatfield J, Albrecht I, Zanolari B, et al. Association of the leukocyte plasma membrane with the actin cytoskeleton through coiled coil-mediated trimeric coronin 1 molecules. Mol Biol Cell 2005; 16:2786-98.

10 Schuller S, Neefjes J, Ottenhoff T, et al. Coronin is involved in uptake of Mycobacterium bovis BCG in human macrophages but not in phagosome maintenance. Cell Microbiol 2001; 3:78593.

11 Itoh S, Suzuki K, Nishihata J, et al. The role of protein kinase C in the transient association of $\mathrm{p} 57$, a coronin family actin-binding protein, with phagosomes. Biol Pharm Bull 2002; 25:837-44.

12 Oku T, Itoh S, Okano M, et al. Two regions responsible for the actin binding of p57, a mammalian coronin family actin-binding protein. Biol Pharm Bull 2003; 26:409-16.

13 Mishima M, Nishida E. Coronin localizes to leading edges and is involved in cell spreading and lamellipodium extension in vertebrate cells. J Cell Sci 1999; 112(Pt 17):2833-42.

14 Spoerl Z, Stumpf M, Noegel AA, Hasse A. Oligomerization, $\mathrm{F}$-actin interaction, and membrane association of the ubiquitous mammalian coronin 3 are mediated by its carboxyl terminus. J Biol Chem 2002; 277:48858-67.

$15 \mathrm{He} \mathrm{H}$, Watanabe T, Zhan X, et al. Role of phosphatidylinositol 4,5-bisphosphate in Ras/Rac-induced disruption of the cortactinactomyosin II complex and malignant transformation. Mol Cell Biol 1998; 18:3829-37.

16 Fulton AB, Wan KM, Penman S. The spatial distribution of polyribosomes in 3T3 cells and the associated assembly of proteins into the skeletal framework. Cell 1980; 20:849-57.

17 Chicka MC, Strehler EE. Alternative splicing of the first intracellular loop of plasma membrane Ca2+-ATPase isoform 2 alters its membrane targeting. J Biol Chem 2003; 278:18464-70.

18 Ramadevi N, Rodriguez J, Roy P. A leucine zipper-like domain is essential for dimerization and encapsidation of bluetongue virus nucleocapsid protein VP4. J Virol 1998; 72:2983-90.

19 Tong Q, Xing S, Jhiang SM. Leucine zipper-mediated dimerization is essential for the PTC1 oncogenic activity. J Biol Chem 1997; 272:9043-7.

20 Richie-Jannetta R, Francis SH, Corbin JD. Dimerization of cGMP-dependent protein kinase Ibeta is mediated by an extensive amino-terminal leucine zipper motif, and dimerization modulates enzyme function. J Biol Chem 2003; 278:50070-9.

21 Bossemeyer D, Engh RA, Kinzel V, et al. Phosphotransferase and substrate binding mechanism of the cAMP-dependent protein kinase catalytic subunit fromporcine heart as deduced from the 2.0 A structure of the complex with $\mathrm{Mn}^{2+}$ adenylyl imidodiphosphate and inhibitor peptide PKI(5-24). EMBO J 1993; 12:849-59.

22 Levy Y, Caflisch A. Flexibility of monomeric and dimeric HIV-1 protease. J Phys Chem B 2003; 107:3068-79.

23 Kranewitter WJ, Ylanne J, Gimona M. UNC-87 is an actin-bundling protein. J Biol Chem 2001; 276:6306-12.

24 Goode BL, Wong JJ, Butty AC, et al. Coronin promotes the rapid assembly and cross-linking of actin filaments and may link the actin and microtubule cytoskeletons in yeast. J Cell Biol 1999; 144:83-98.

Edited by Athanasios G Papavassiliou 